\title{
Some flow patterns within ventilation strategy coupled to energy efficiency
}

\author{
Souad Morsli ${ }^{1,2,}{ }^{*}$, Rachid Bennacer ${ }^{3,4}$, Mohammed El Ganaoui ${ }^{5}$, Harry Ramenah $^{2}$, and Alain Carmasol $^{6}$ \\ ${ }^{1}$ University of Science and Technology Mohamed Boudiaf / LSIM, Oran, Algeria \\ ${ }^{2}$ University of Lorraine, LCOMS-Metz, France \\ ${ }^{3}$ LMT/ENS - Paris Saclay/CNRS/Univ. Paris Saclay, 61 av. du Président Wilson, 94235 Cachan, France \\ ${ }^{4}$ Tianjin Key Lab of Refrigeration Tech., Tianjin Univ. of Commerce, Tianjin City 300134, PR China \\ ${ }^{5}$ University of Lorraine, Henri Poincaré Institute/ LERMAB, Longwy, France \\ ${ }^{6}$ University of Lorraine, ENIM, Metz, France
}

Received: 14 August 2019 / Received in final form: 15 November 2019 / Accepted: 28 November 2019

\begin{abstract}
Energy and buildings are increasingly becoming subjects for investigations, especially for the indoor air quality domain coupled to energy demand. The physics of fluids flowing inside enclosures bring basic models to understand and build better schemes. This paper is devoted to studying ventilation strategies in regards to Indoor Air Quality (IAQ) and energy efficiency in floor refreshing houses. A room model is considered in a simplified level, as a cavity heated on the external sidewall and cooled on the bottom ground surface. The external air injector is at variable positions and interacting with the needed cooling power; the air quality (mixing ability) and thermal comfort are also studied. The cooling efficiency inside the considered volume and the average air temperature are analyzed for a given temperature difference characterizing the natural convection level (Rayleigh number, $\mathrm{Ra}=10^{6}$ ) and a horizontal ventilation (moderate Reynolds number $\operatorname{Re}=10^{2}$ ). An obtained complex flow structure indicates that the natural convection and the forced flow (ventilation) act directly on the resulting patterns, mixing ability, heat exchange which in a straight line affect the thermal comfort and in fine the energy cost (cooling requirement).
\end{abstract}

\section{Introduction}

With growing interest in sustainable development and the fight against climate change, it is urgent to reduce energy expenditure in buildings in order to meet the GHG emission reduction requirements (Kyoto Protocol). For example, in 2002, Europe adopted Directive 2002/91/EC aiming to improve the energy performance of buildings within the community by taking climate and site into consideration to the same degree as the requirements for comfort and indoor environmental quality and profitability.

Thermal comfort is currently recognized and this justify the demand in modern buildings. Because of its impact on the indoor environment quality, on the health and on the productivity of the occupant spending three quarters of his time inside. It simply involves the complex interaction between the human and the environment.

Human body reacts by a dynamic interaction mobilizing a set of retroactive reactions, voluntary and involuntary, which allow controlling the thermal neighboring exchanges in order to satisfy the requirements of homeothermy. Depending on the intensity of heat

\footnotetext{
^ Contribution to the topical issue "Materials for energy harvesting, conversion, storage and environmental engineering (Icome 2018)", edited by Jean-Michel Nunzi, Rachid Bennacer, Mohammed El Ganaoui, Mohamed El Jouad.

* e-mail: Morsli.souad@yahoo.fr
}

exchange and the reactions involved in a given environment, the body may feel a sensation of thermal neutrality, warmth or freshness. He may be hot or cold in extreme conditions that can plunge him into hyperthermia or hypothermia during prolonged exposure putting his life at risk. The thermal sensation thus generated gives rise or not to the discomfort. If the sensory zone of neither hot nor cold allows for the majority people to guarantee the absence of thermal discomfort, it cannot pretend to ensure the comfort [1].

Accordingly, the designer must provide the necessary answers for the building in order to enable it to achieve its functional objectives while justifying, rightly or wrongly, the installation of ambient equipment (heating, ventilation and air conditioning).

The urgent need for energy savings should not compromise the quality of the indoor thermal environment. This requires a new vision on thermal comfort currently considered under an analytical approach in standards.

The analytical approach provides a reductive vision of thermal comfort based on physical and physiological mechanisms.

The thermal environment is characterized by four physical quantities (the air temperature, radiation temperature, humidity and air velocity). These variables react with the activity and clothing of the human body to establish its thermal state and together constitute the six basic parameters of heat exchange between man and his 
immediate environment. Nevertheless, beyond these variables, the thermal perception of an environment can be influenced by physiological, psychological and sociological variables; acclimation can alter thermal sensations, as well as behaviors, habituation and expectations of occupants in their living environments.

Involved coupled phenomena concern nonlinear effect and may be sensitive to some parameters. Several approaches are possible as taking measurement using empirical estimates or in a better way developing a numerical simulation. Firstly, investigation was conducted in 2D simple cases to validate occurrence of phenomena and unavoidably the progress ask a 3D extension to feet with the physics.

Historically, ventilation was naturally due to leaks, window openings and chimney flues. Nowadays, the reinforcement of the requirements with respect to the air tightness makes the installation of a ventilation system essential to avoid the phenomenon of confinement and master the air mass flow rate [2].

Among the various adaptive actions that the occupant can undertake, Fabi et al. [3] have shown that the action on the window has a great influence on energy consumption, comfort and the IAQ. Brundrett [4] states on the opening/ closing mode of the window and finds a correlation with the average daily temperature and the opening frequency. Andersen et al. [5] confirmed this by using a measurement made in 15 dwellings.

It was studied for eight months that the opening/ closing practices of the windows were different depending on the type of housing. The concentration of $\mathrm{CO}_{2}$ and the outside temperature are the two main variables used to explain the probabilities of actions on windows.

Warren and Parkins [6] had already pointed out, in the study of five three-month office buildings with different climatic conditions that the opening of windows correlated with the outside temperature and to a lesser extent with solar radiation and wind speed. They also determined that the use of the window was due to the need for good indoor air quality and efficient temperature control especially in summer.

Also, according to Van den Wymelenberg [7], the second factor having an influence on the position of occultation is the season. Pigg et al. [8], Inkarojrit [9] and Nicol et al. [10] in their study show that in winter, $14-18 \%$ of shutters are closed, $34-40 \%$ in spring, $34-42 \%$ in summer and $28-36 \%$ are in autumn.

The changes that can be observed according to the seasons can also be related to the weather. Indeed, several studies (REA [11], Nicol et al. [10]) show that depending on the type of sky (sunny, intermediate, and covered), occultations are in different positions. They are mainly open during cloudy days and closed on sunny days, which confirms the previous hypothesis: occultations make it possible to protect themselves from direct solar radiation. Mahdavi [12] then links the frequency of action on occultation's with the global vertical irradiation incident on the facade.

For buildings, windows provide important inside/ outside interface concerning numerous compromise inducing light, sight, view and intimacy. This induced several studies [13-17]. Haldi and Robinson [18] shows that indoor temperature plays an important role in predicting actions on occultation, which suggests that occupants reaction to a ventilated zone may be subjected to flows from ventilation systems as well as to flows resulting from leaks in the envelope. When the zone is subjected to a controlled air flow in the case of a completely sealed room and equipped with mechanical ventilation, it is possible to estimate the ventilation rates by direct measurements on ducts. However, when it comes to measuring including infiltration, tracer gas techniques are the most appropriate [19]. In addition, when it comes to natural or hybrid ventilation systems, it is almost impossible to measure ventilation rates for an area with more than one opening [20]. On the other hand, the tracer gas techniques are the only ones that measure the parameters and indices of ventilation efficiency.

Roulet's calculation of air exchange efficiency $[21,22]$ is based on the measurement of tracer gas concentrations during extraction. This allows measuring simultaneously the nominal time constant (age local extraction) and the average age of the ventilated area depending on the concentration in the extraction.

ASHRAE Standard 129 [23], which restricts ventilation efficiency to the breathing zone, offers a variant of calculation. Indeed, it recommends the calculation of the ventilation efficiency not for the whole of the ventilated zone but only to the breathing zone. Thus, the calculation of the mean age of the ventilated zone is not based on the measurement of the local age at extraction. The nominal time constant is measured at extraction and weighted according to extraction rates. Note that this method is valid even in the case where the ventilation system has several extractions.

The important quantity of listed studies focused on occultation's placement, weather, seasons and occupant uses, this suggests an important correlation between the air circulation and expected comfort. Then the use of the CFD (Computational Fluid Dynamic) tools is recommended.

Many other studies have been conducted to better understand the importance of indoor air quality coupled to energy context and smart buildings [24-26].

This paper is a continuation of the works of Morsli et al. [27,28]. Particularly, the same scheme of the paper [28] is considered. Here, the study focuses on the input/ output configuration. When modified, the whole strategy is consequently affected. Namely, the present study considers a housing module with a cold floor and a hot vertical wall. The other parts are not heat exchanging. The air arrives at the top of the right vertical wall, while the outlet is supposed to vary. Actually, various scénariis were studied corresponding to different locations on the grille (Fig. 1). For the thermo-physical properties, some ones as the previous works are adopted.

The work provides estimate based on residence time of incoming airflow and the interaction with thermal conditions and environment. This physical phenomena understanding allows controlling operating parameters leading to occupant comfort. 


\section{Computational model for IAQ problem}

Computational Fluid Dynamics (CFD) has the advantage, compared to conventional tools, of being able to accurately write the air jet and thus optimize the positioning of the device and the operating settings.

The room subject to various scenariis of ventilation is modeled as an enclosure $(L x \times L y \times L z)$ containing air $(P r=0.71)$ and submitted to side heating (solar effect) and floor cooling. Other connecting surfaces are assumed adiabatic. The corresponding computational cavity is sketched in Figure 1.

The fresh air is injected from outdoor and is at the same temperature of the heated side $\left(T_{H}\right)$. We have a closed window and no leakage, so we extract the same quantity of air from a similar rectangular opening (size: $d=0.44$ and $h=0.15$ ) located on the opposite side, i.e. $X=1$, and centered on different position (see Tab. 1). The flow is assumed in steady state at moderate Re number value. The air was assumed to be Newtonian in incompressible flow and within Boussinesq approximation.

It has been chosen to solve the present coupled problem by using numerical simulation allowing large explorating possibilities and access to field details. The simulation allows a large potential of understanding phenomena and contributing to their control. Details of the problem definition, governing equations, computational tools and finally simulations will develop such approach naturally and will be submitted to verification and validation [28].

Variables are reduced as:

$$
\begin{aligned}
& (X, Y, Z)=(x, y, z) / L_{z}, P=p /\left(\rho v^{2}\right), \vec{V}=\vec{v} L_{z} / v, \\
& \theta=\left(T-T_{C}\right) /\left(T_{H}-T_{C}\right)
\end{aligned}
$$

where $v$ is the kinematical viscosity and $\vec{V}$ is the velocity. The air mass conservation equation, momentum and energy in non-dimensional form for a given single area are:

$$
\begin{gathered}
\vec{\nabla} \cdot \vec{V}=0 \\
(\vec{V} \cdot \vec{\nabla}) \vec{V}=-\vec{\nabla} P+\nabla^{2} \vec{V}+(R a / P r) \theta \vec{k} \\
\vec{V} \cdot \nabla \theta=\frac{1}{\operatorname{Pr}} \nabla^{2} \theta
\end{gathered}
$$

with $\operatorname{Pr}=v / \alpha$ (Prandtl number) and $R a$ the Rayleigh number. No slip conditions are assumed $(\vec{V}=\overrightarrow{0})$ on all solid boundaries, except on the ventilating opening that are at constant velocity.

$U=R e$ or $U=-R e$ depending on the ventilation

strategies (injection or extraction respectively).

The different considered cases (for extraction or injection) for different position of the ventilation opening on the inner wall (opposing to the external heated wall) are summarized in Table 1 . The different cases are numbered from 1 to 3 along the $Y$ axis and 0 to 4 along the $Z$ axis. They will be named based on the line and row index, i.e. the $\mathrm{P} 02$ will be the second case along $Y$ and the 0 case along $Z$.

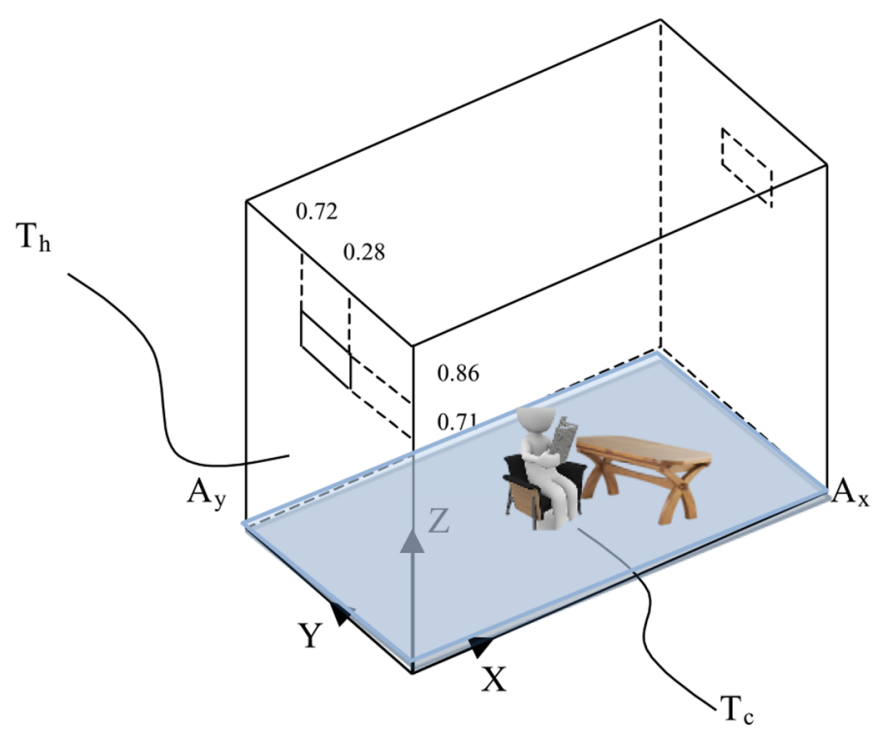

$-a-$

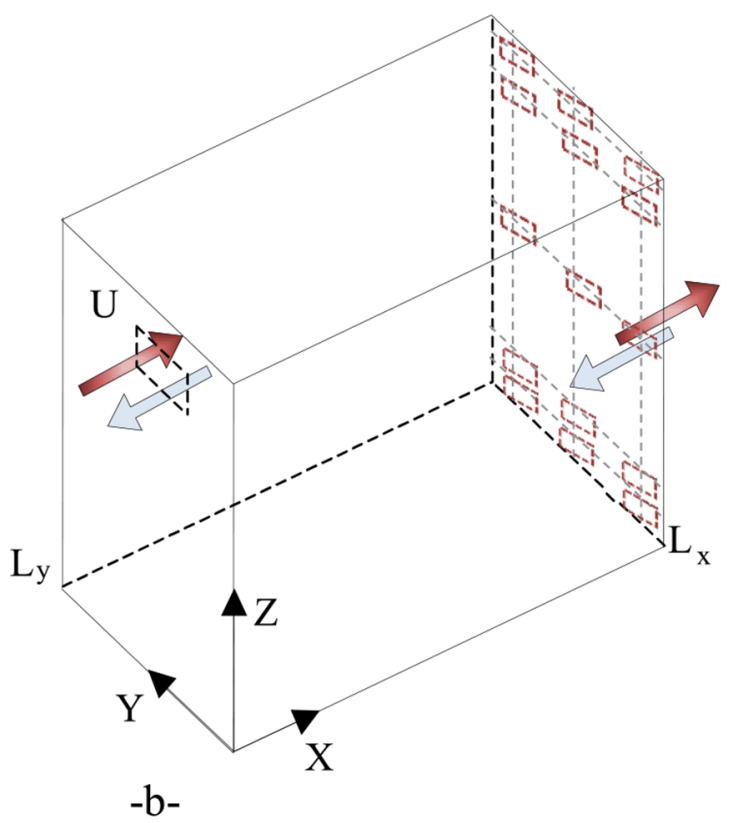

Fig. 1. Configuration, boundary conditions (a). Ventilation strategies for various positions (b).

Table 1. List of considered cases according to $Z-Y$ central position of the window (size: $\Delta Y=0.44$ and $\Delta Z=0.15$, Fig. 1a).

\begin{tabular}{llll}
\hline & \multicolumn{3}{c}{$Y$ direction } \\
\cline { 2 - 4 }$Z$ direction & 1 & 2 & 3 \\
\hline 0 & $0.78-0.925$ & $(\mathrm{P} 02) 0.5-0.925$ & $0.22-0.925$ \\
1 & $0.78-0.785$ & $0.5-0.785$ & $0.22-0.785$ \\
2 & $0.78-0.500$ & $0.5-0.500$ & $0.22-0.500$ \\
3 & $0.78-0.215$ & $0.5-0.215$ & $0.22-0.215$ \\
4 & $0.78-0.075$ & $0.5-0.075(\mathrm{P} 42)$ & $0.22-0.075$ \\
\hline
\end{tabular}



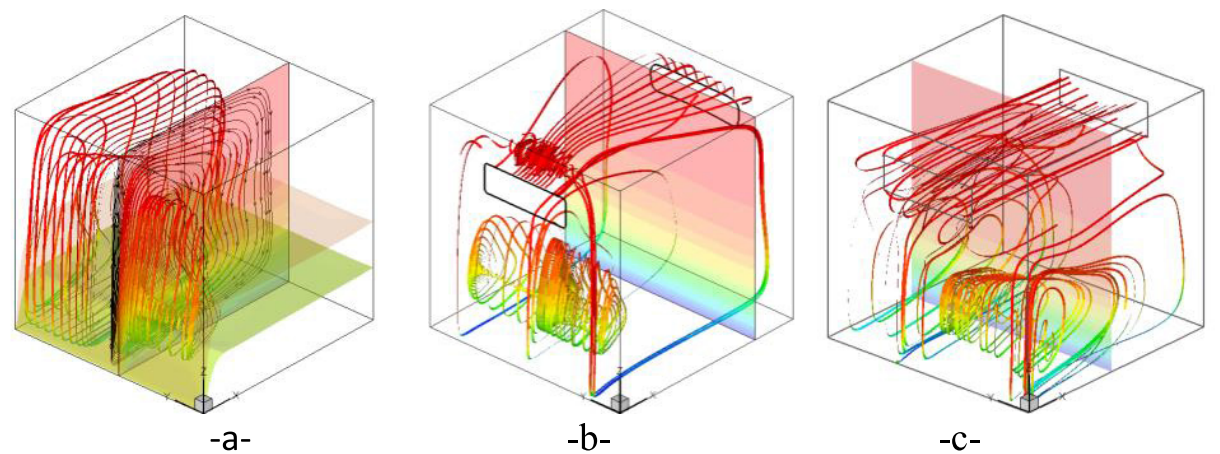

Fig. 2. Dynamic and temperature field on non-ventilated (a), ventilated cavity 'injection' (b), and ventilated cavity opposing flow extraction (c).

\subsection{Computational tools}

As problem refers to the Navier-Stokes equations with particular boundary conditions, the numerical approach is inevitable leading to a system of algebraic equations that can be numerically solved. The simulation was performed by using the industrial code CFD Fluent [29]. On the presented results, different meshes are considered. The tests were carried out for grids ranging from $150^{3}$ to $250^{3}$. All these grids were refined close to the walls in order to take into account stiff gradient neighboring the boundaries. A selected mesh $200^{3}$ will be used for the computations conducted in this study.

\section{Results and discussion}

CFD results will be analyzed on terms of thermal and dynamic fields. The face contains multiple possible opening $P_{i j}$ indicating the location of the ventilation opening; $i$ refers to the row and $j$ to the column (see Tab. 1). Contours in the enclosure are presented allowing the discussion for different ventilating position (see Fig. 1b).

Temperature and flow structure for non-ventilated and ventilated P12 case are depicted in Figure 2. This figure shows temperature and flow structure for non-ventilated (left), ventilated 'injection' (center) and opposing flow 'extraction' (right).

Without ventilation (Fig. 2a) the thermal buoyancy force act on the flow in the direct vicinity of the vertical wall and is in antagonism with the stabilizing applied floor cooling. The flow is mainly $2 \mathrm{D}$ structure if excluding the effect of lateral surfaces. However, for the two other ventilation strategies (injection or extraction air renew), the 2D symmetry breaking is observable and a more complex flow settle and 3D flow character symmetrical or not symmetrical are obtained.

It is obvious that natural convection is controlling the flow structure when no ventilation (Fig. 2a), the heated air rise along the vertical heated wall inducing the main loop. When ventilation is applied, we are facing competition between the previous underlined main loop and added horizontal flow. The first observed cases are the cooperating situation where the injected flow is from the hot surface (Fig. 2b) and the opposing case where the injected flow is in reverse direction and again the main lower loop (Fig. 2c). The reverse situation induces a recirculating third cell between the main loop and the horizontal ventilation flow. Such recirculating cell aims to reduce the shear stress between the natural and the forced convection. The resulting flow modifies the heat exchange on the heated wall and on the cooled floor. The resulting complex flow affect the temperature field, the IAQ, and the energy demand to keep the required temperature (comfort). We will discuss below the consequence of both inverting the flow direction and the position of the air opening on the left wall.

Analyzing the thermal configuration, the presence of a hot and a cold boundary with common interface result on a singular contact line in favor of high heat transfer. A stiff temperature gradient neighboring the floor is then observed. The iso-surfaces temperatures are parallel to the bottom surface except neighboring the contact line. The temperature increases toward the ceiling. This suggests developing a technical approach to avoid sharp gradients and possible situation not in favor of the expected thermal comfort.

Since such floor cooling use, answer to the energy demand to the thermal comfort requirement, the temperature distribution approximately to the active thermal wall is directly related to local transfer (Nusselt number). In the present study, we obtain a thermally stratified area in the core of the enclosure because of the downward flow on the opposing vertical surface.

The local Nusselt number on the two active thermal wall are represented in Figure 3 for the chosen ventilating opening position for both injection and extraction, for $R a=10^{3}$ and $R e=10^{2}$. We recall that the injected renew air is at hot temperature (arriving from external hot climate).

The local Nusselt map on both surfaces, vertical and horizontal, are presented in planar way as sketched on the top/left figure underlining the left and bottom cases beside the figure. The solid rectangular line represents the opening ventilating on the considered wall while the opening on the adiabatic opposing wall is just illustrated by the dashed 


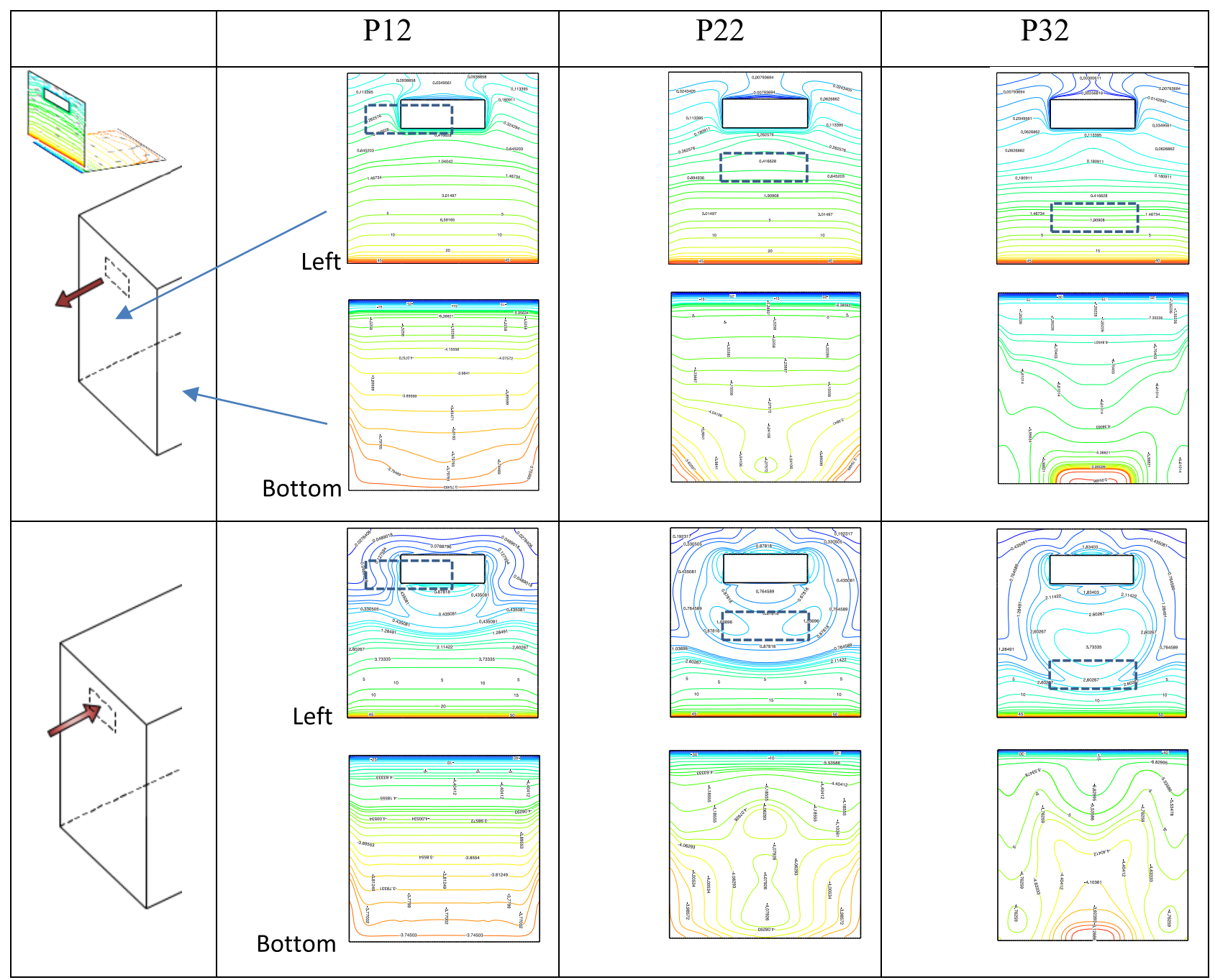

Fig. 3. Local heat transfer (Nusselt number $N u_{Y Z}$ ) on bottom and lateral wall for different ventilating position in cooperating and opposing cases.

rectangular one. Three representative cases namely (P12, P22, P32), corresponding to the central and sliding vertically the opposing ventilation opening, illustrate the effect on the heat transfer, especially when the hot injected air is in the vicinity of the floor cooling. On such chosen observation, we can find again the previous mentioned singularity on the two surfaces line contact (floor-wall connection) with maximum heat transfer as illustrated by the dense horizontal line (red to green). The transfer decreases on both surfaces for distance from the contact line increase. Such local $N u$ number tends to reach constant value on the horizontal direction except for the case when the ventilating window is neighboring the floor cooling.

It is complex to extract universal conclusion on local heat transfer because of the effect of the location of the air window, the lateral walls and the effect of the dynamic strategy of injection/extraction. The decrease of heat transfer on upper part of the heated surface could be illustrated with heat transfer (averaged on $Y$, Eq. (5))

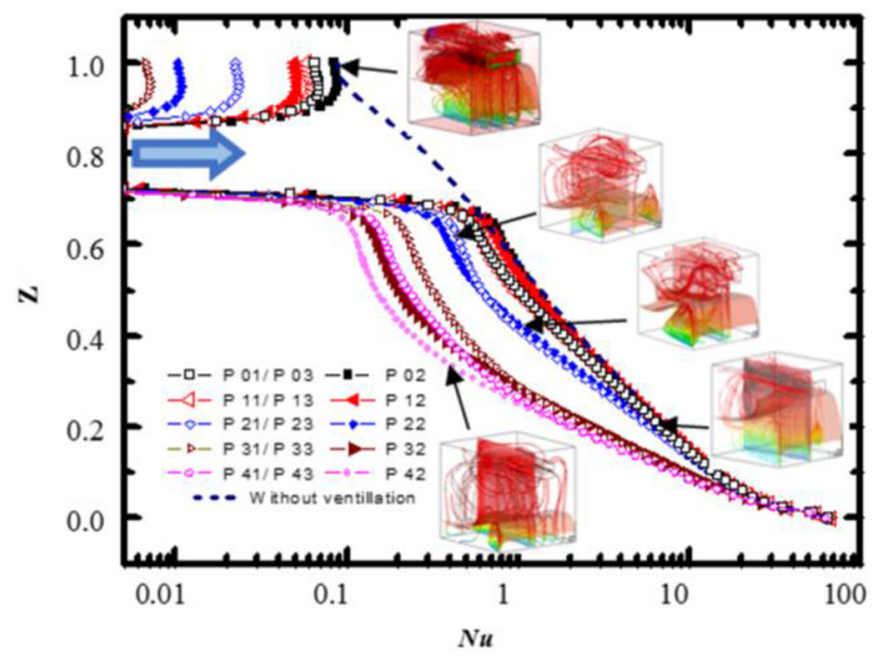

Fig. 4. Average Nusselt versus vertical position $Z(\overline{N u}(Z))$ for the different opening locations, in the cooperating ventilating strategy. 


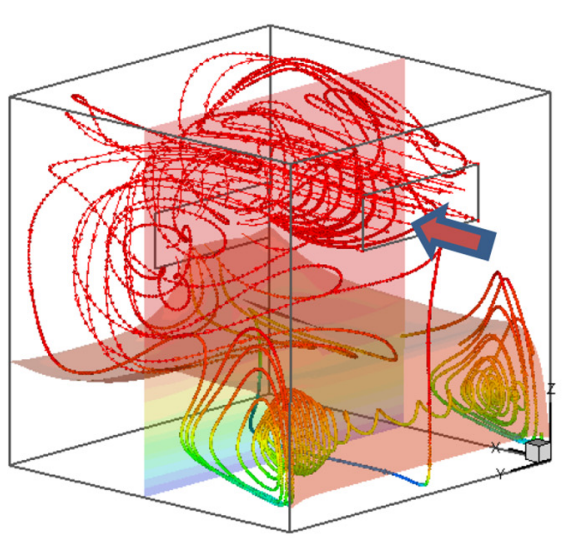

a
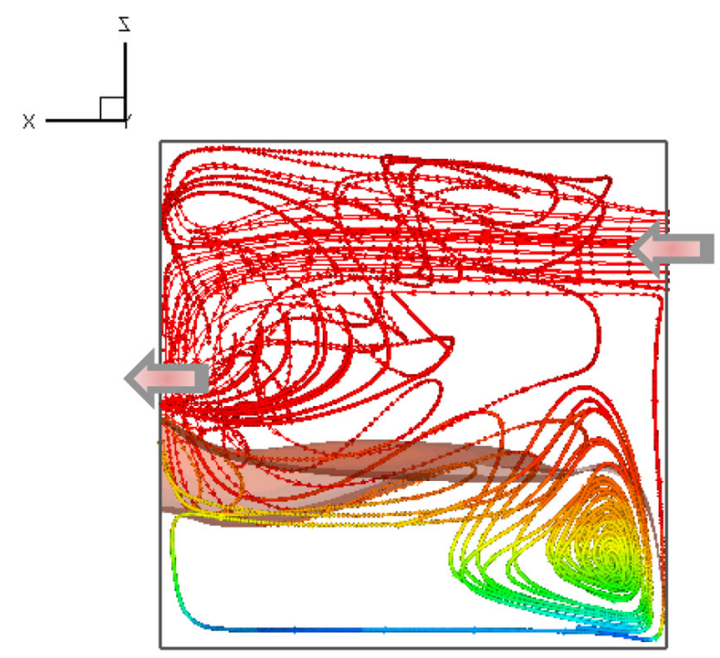

C

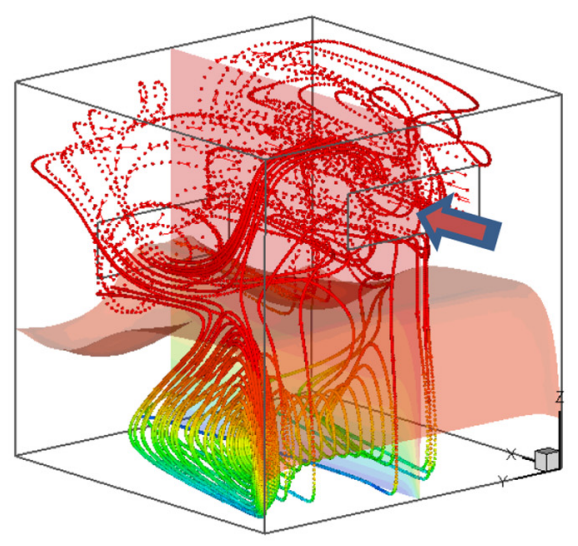

b
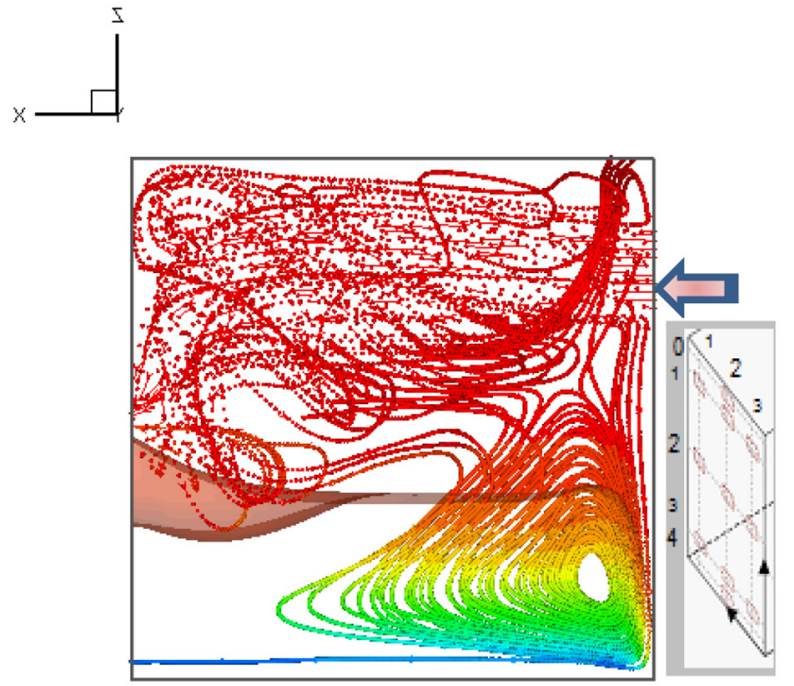

d

\begin{tabular}{l|r|r} 
P21 P22 & P2
\end{tabular}

Fig. 5. Flow and thermal isosurface in cooperating flow injection, $3 \mathrm{D}$ view (a) P21; (b) P22 and the 2D (XZ view) (c) P21; (d) P22.

versus the $Z$ position.

$$
\overline{N u}(Z)=\int_{Y=0}^{1} N u_{Y Z} d y
$$

The comparison between the different analyzed situations in cooperating case is summarized in Figure 4. In the same figure, the reference case of purely natural convective situation (in black dashed line) is plotted. The filled symbols are for the vertical mid line opening positions $\left(\mathrm{P} \_2\right)$ and the hollow symbols are for the horizontally sliding opening (to left $\mathrm{P}_{1} 1$ or to right $\mathrm{P} 3$, which are equivalent and symmetrical to the vertical $\bar{Y}$-mid plan). It is evident that the heat transfer decrease from the bottom toward the top due to the previously underlined singularity on the contact line. The second observation is the complexity of exchange where we observe a localized decrease in relation to the reference depending on the ventilation position. This is a direct consequence of the flow structure, which reduces the size of the main loop. The recirculating loop sizes are illustrated by the inserted stamps within the figures.

On the other hand, part of the observed heat decrease is a consequence of the flow going in the third direction following the impact jet on the opposing wall corresponding to the $\mathrm{P}_{-} 1$ and $\mathrm{P}_{3} 3$ cases.

It has been locally observed that some increase of the Z-local heat transfer on the top occurs when it decreases on the bottom especially for the border situation (injection close to ceiling). Such complexity is visible on the position sliding windows in horizontal direction where an increase is observed in lower part (relative to P32 and P42) or a 


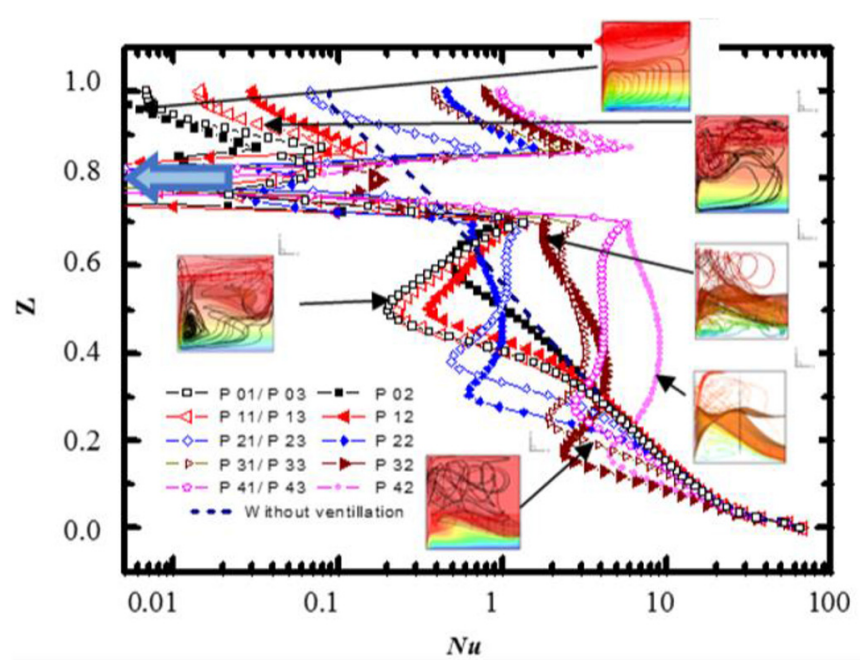

Fig. 6. Average Nusselt versus the vertical position $Z(\overline{N u}(Z))$ for the different opening position, in the opposing ventilating strategy.

decrease in other cases (P02). We can also observe almost the same equivalent heat transfer on the main lower part as for P21 and P22. The only difference is on the part above the air-extracting opening (Fig. 4). The two obtained complex flow exhibit obviously a symmetry breaking (from symmetrical to non-symmetrical for sliding opening toward the border) as illustrated in Figure $5 \mathrm{a}$ and $\mathrm{b}$. The complexity of the flow in upper part confirms the previous discussions about the impact jet for P21 case. To illustrate the non-symmetry, the stream traces are colored by the thermal field and a thermal iso-surface helps to visualize the non-symmetry. The side view confirm the more complex flow in the symmetrical case P22 (Fig. 5b and d) inducing an increase on some part and a decrease on the other part of the local heat transfer along $Y$ direction. Such change in both directions is not so visible on the $\overline{N u}(Z)$ (Fig. 4) and illustrates clearly a threshold where the upper flow (ventilation) is in limit equilibrium with the lower natural convective loop. The case P21 exhibits a helicoidally flow which do not enhance enough the lower cell (weaker than the one in P22) but with more intensive flow impact jet on the opposing wall. The main core of the domain is filled by the recirculating injected flow before getting out. If renew air is injected in reverse way (extraction case), the interaction in both direction could be more complex and is discussed below.

The induced transfer $\overline{N u}(Z)$ in reverse flow case (Fig. 6) is more multifaceted with global three main remarks:

- the heat transfer decrease in the lower part $(Z<0.2)$ for most cases;

- the heat transfer increase for $Z>0.25$ for lower ventilation position (P42, P32) and also on upper part for P21;

- a minimum heat transfer is observed for the different cases for $Z$ between 0.15 and 0.6 and are indicated by black arrows. Such minimum are the position of the intermediate cell between the two opposing flow, i.e. forced upper and natural lower convection. To illustrate the heat transfer and flow structure complexity we inserted in Figure 6 the flow patterns as stamps.

The situation of the two opposing flow induces a damping of the lower natural convective cell (see Fig. 7). Where the natural loop is squeezed below the forced ventilating flow (Fig. 7a and b) and the horizontal flow impacts the opposing heated wall (Fig. 7c and d) inducing the minimum heat transfer, which situates between the contrarotative flow cells.

Concerning the IAQ, the complex and helicoidally flow is better because it allows more mixing and it avoids large recirculating flow in isolated domain. More homogeneous temperature field is also obtained for the P32, illustrated in Figure $7 \mathrm{~b}$, where the isotherms 0.7 show that the refreshed part cover almost more than the half of the domain (room).

Such complex thermo-fluidic exchange modifies locally the heat transfer with some increase and decrease on different zones for the same case. The induced global heat transfer - and more specifically the cooling needs - is represented by the average heat transfer on the cooling surface. Such Nusselt is equivalent to the Nusselt on the heated surface completed by the extra energy balance on the open flow between the inflow and outflow.

$$
N u_{A v g}=\int_{Z=0}^{1} \overline{N u}(Z) d z=\int_{Y=0}^{1} \int_{Z=0}^{1} N u_{Y Z} d y d z
$$

The corresponding needed cooling is summarized for the different explored ventilation position in Figure 8. The different positions of the injecting opening are represented by rectangular dashed line on the $Y-Z$ plan. On each central position we represent the corresponding $\mathrm{Nu}$ bottom (cooling needed) and we obtain finally the isoNusselt corresponding to the explored area. The two analysed situations, injected and extracted, are represented, respectively, by Figure $8 \mathrm{a}$ and b. The Nusselt is weakly sensitive when sliding the opening window along the $Y$ direction contrary to the more sensitivity with sliding the opening along $Z$. This confirms the previously underlined tendency of the increase in cooling needs with the opening position more close to the cooling floor. For all positions, $N u$ is almost constant for $Z$ center higher than 0.4 and 0.25 for injection and extraction, respectively. As the average Nusselt bottom is not sensitive to the $Y$ center position of the opening, we can plot the cooling needed versus the $Z_{\text {center }}$ position of the opening in order to compare the two ventilations strategy. Such result is summarized in Figure 9 where the cooling requirement exhibit two tendency: important increase (exponential) when the opening becomes close to the floor and relatively power law tendency for non-small $Z$ and above a limit position $Z_{\text {limit }}$ depending on the ventilation strategy. The two obtained function of cooling needed versus $Z_{\text {center }}$ are equivalent and follow $\overline{N u}=A \times Z^{0.28}$ and are represented in Figure 9 for injection and extraction, $A=4.8$ and 4.1, respectively. We demonstrate also the best mixing ability on IAQ point of view, which is antagonist with the cooling, need to decrease. This representation suggests to explore 


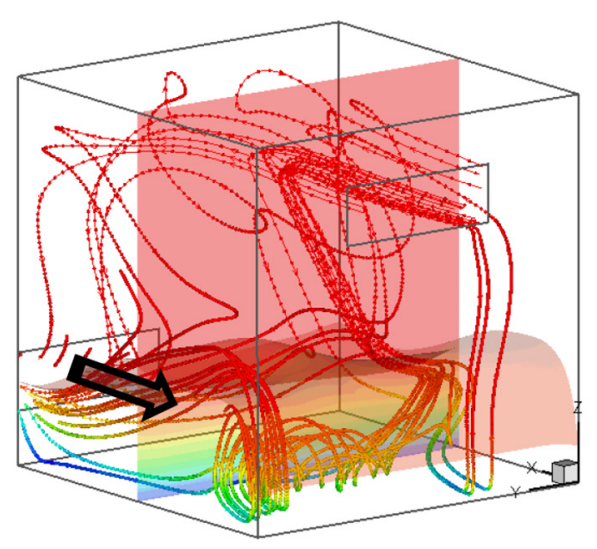

a

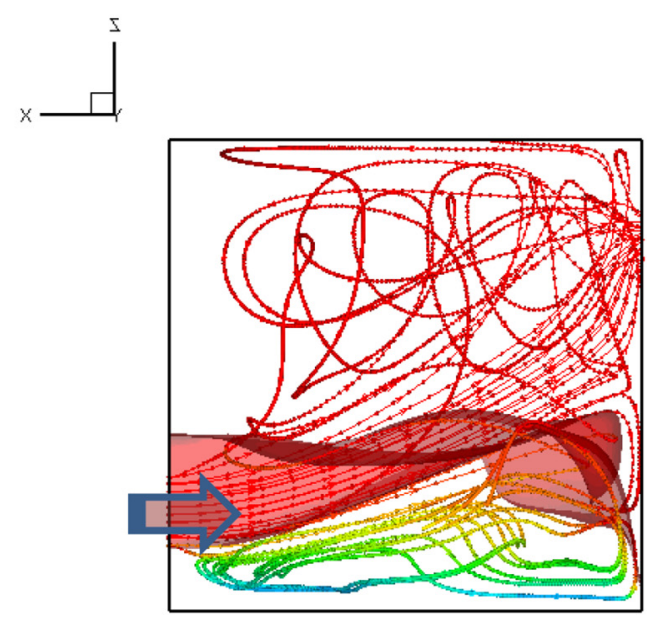

C

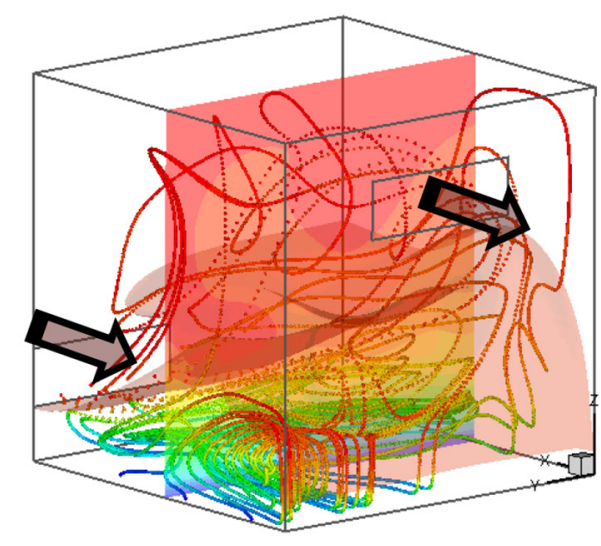

b
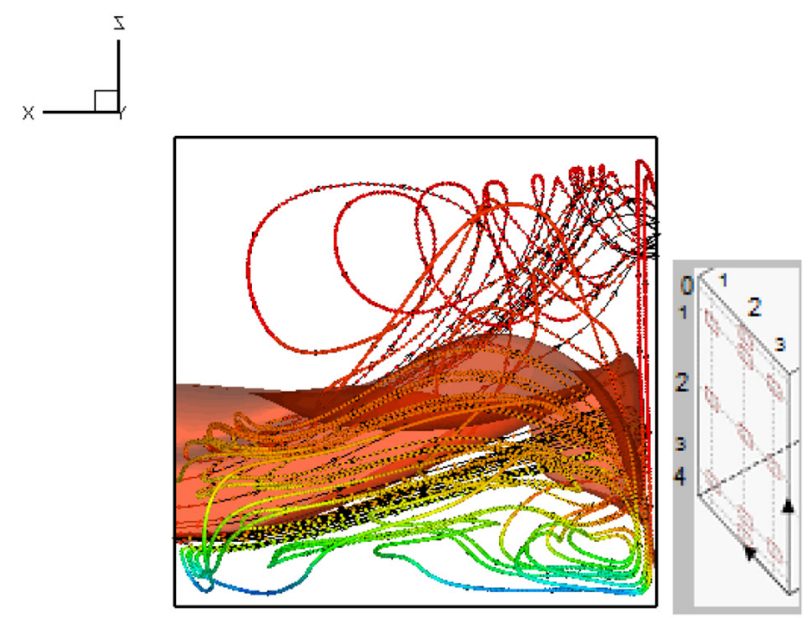

d

P31

P32

Fig. 7. 3D view of the domain with opposing flow injection (a); (b) (P31, P32 respectively), and the 2D (XZ view) of the domain with opposing flow injection (c) and (d) (P31, P32 respectively).

the cooling need viewed from a point of interest and to evaluate economic impact, which follow in further work.

\section{Conclusion}

The research conducted in this work was aimed to study numerically and understand the phenomena of ventilation. For that a cubic ventilated cavity with different air outlet positions was investigated. The coupled dynamic and thermal fields have been studied for a Rayleigh number equal to $10^{6}$ and Reynolds number equal to $10^{2}$. The external air injector is placed at variable positions influencing the needed cooling power, the air quality (mixing ability) and thermal comfort. From the presented results, we can summarize some concluding remarks in the following.

Without ventilation the thermal buoyancy forces act on the flow in the direct vicinity of the vertical wall and are in antagonism with the stabilizing applied to floor cooling. The flow is mainly 2D structure if excluding the lateral surfaces effects. However, for the two other ventilation strategies (injection or extraction air renew), the $2 \mathrm{D}$ symmetry breaking is observable and a more complex flow settle and 3D flow character symmetrical or not symmetrical are obtained.

When ventilation is applied, we face competition between the main loop constituting the flow and the added horizontal flow. Situation leads to cooperating and opposing flows. However, the presence of the recirculating third cell aims to reduce the shear stress between the 

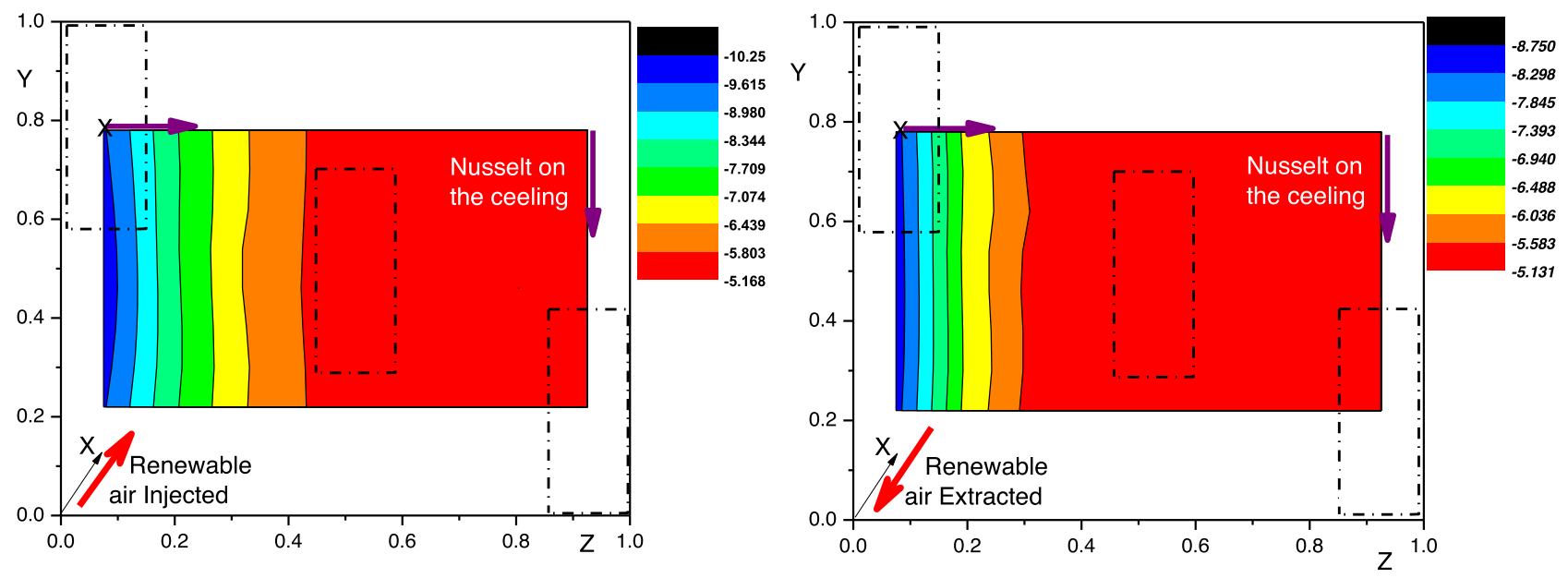

Fig. 8. Induced heat exchange (Nusselt) on cold surface adjacent to the bottom position by changing the position for injection and extraction cases.

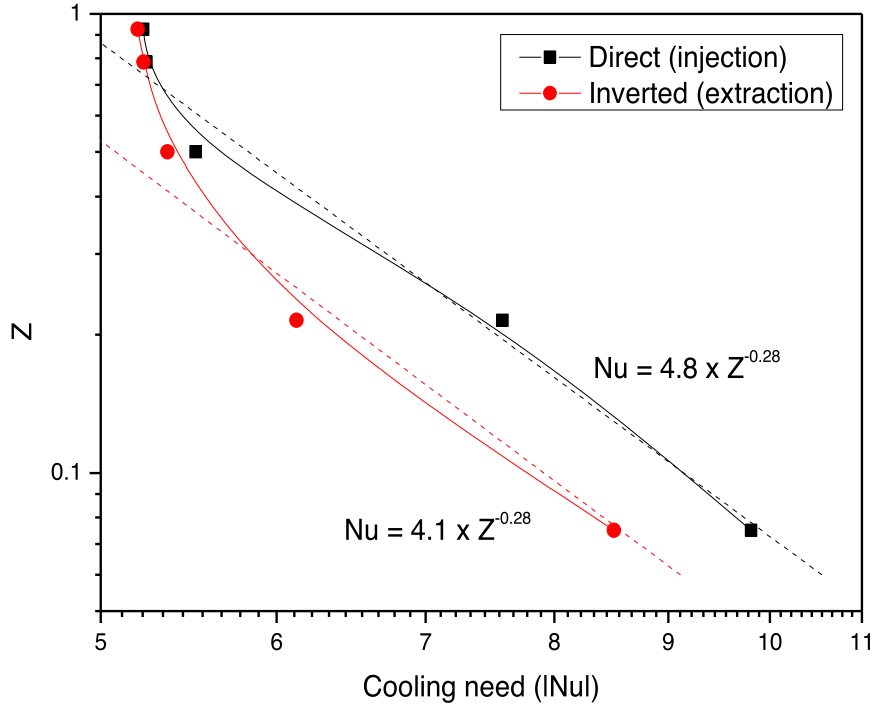

Fig. 9. Representation in terms of cooling need on the direct injection and the air extraction strategies at different vertical locations.

natural and the forced convection. The complex convective patterns affect the temperature field, the IAQ, and the energy demand to keep the requested comfort.

A thermally stratified area in the core of the enclosure is obtained. Local $N u$ number tends to reach constant value on the horizontal direction except for the case when the ventilating window is neighboring the floor cooling.

The impacting jet on the opposing wall results in decreasing the heat flow according to the contribution of the third direction.

Some local behaviors are described and analyzed. If renew air is injected in reverse way (extraction case), the interaction in both direction could be more complex.
It has been observed that the presence of a helicoidally flow allows more mixing and avoids large recirculating flow in isolated domain. Such complex thermo-fluidic exchange modifies locally the heat transfer with some increase and decrease in different zones.

Paper reveals, in addition, the best mixing ability on IAQ point of view, which is antagonist with the cooling, needs to decrease. This representation suggests to explore the cooling need viewed from a point of interest and to evaluate economic impact, which follow in further work.

\section{Nomenclature}

$g \quad$ Gravitational acceleration $\left[\mathrm{m} \mathrm{s}^{-2}\right]$

$L_{(x, y, z)}$ Cavity dimensions in $(x, y, z)$ directions $[\mathrm{m}]$

$T, \quad$ Dimensional temperature $[\mathrm{K}]$

$u, v, w$ Dimensionless velocity components

$x, y, z \quad$ Dimensionless cartesian coordinates

Greek symbols

$\alpha \quad$ Thermal diffusivity $\left[\mathrm{m}^{2} \mathrm{~s}^{-1}\right]$

$\beta_{T}$ Volumetric expansion coefficient $\left[\mathrm{K}^{-1}\right]$

$\mu \quad$ Dynamic viscosity $\left[\mathrm{kg} \mathrm{m}^{-1} \mathrm{~s}\right]$

$v \quad$ Kinematic viscosity $\left[\mathrm{m}^{2} \mathrm{~s}^{-1}\right]$

$\rho \quad$ Density $\mathrm{kg} / \mathrm{m}^{3}$

$\theta$ Dimensionless temperature $\left(T-T_{C}\right) /\left(T_{H}-T_{C}\right)$

Non-dimensional numbers

$A_{(x, y)} \quad x, y$ aspect ratio, $L_{(x, y)} / L_{z}$

$h, d \quad$ Dimensionless ventilation opening

$N u_{\text {down }} \quad N u$ on bottom surface $=\left.\int_{x=0}^{1} \int_{y=0}^{1} \frac{\partial \theta}{\partial z}\right|_{z=0} d x d y$

$N u_{\text {Lat }} \quad N u$ on lateral walls $=\left.\int_{y=0}^{1} \int_{z=0}^{1} \frac{\partial \theta}{\partial x}\right|_{x=0,1} d y d z$

$\operatorname{Pr} \quad$ Prandtl number, $=v / \alpha$

Ra Rayleigh number, $g \beta_{T} \Delta T L_{Z}^{3} /(v \alpha)$ 
The authors are grateful to LCOMS \& LERMAB Lab, University de Lorraine Metz, France and 'Tous Chercheurs' project for providing support on this work. They also thank PHC Maghreb and CPER - University of Lorraine.

\section{Author contribution statement}

Morsli Souad: Numerical calculation, counting the results and drawing curves. Bennacer Rachid: Physical interpretation (read and corrected the paper). El Ganaoui Mohammed: Mathmetical Model, validation and verification of results (read and corrected the paper). Harry Ramenah: Write part of the paper. Carmasol Alain: Solved an interesting question between the submission and the correction of the reviewer's comments.

\section{References}

1. V. Candas, Confort thermique. In: Génie énergétique. Vol. BE 4. Paris: Techniques de l'ingénieur, p. BE 9085 (1998)

2. G.C. Da Graça, P. Linden, Build. Environ. 107, 263 (2016)

3. V. Fabi, R.V. Andersen, S. Corgnati, B.W. Olesen, Build. Environ. 58, 188 (2012)

4. G.W. Brundrett, Int. J. Energy Res. 1, 289 (1977)

5. R.V. Andersen, J. Toftum Fabi, S.P. Corgnati, B.W. Olesen, Build. Environ. 69, 101 (2013)

6. P.R. Warren, L.M. Parkins, Window-opening behavior in office buildings, in Technical \&5 Symposium Papers Presented at the 1984 Winter Meeting of the American Society of Heating, Refrigerating and Air-Conditioning Engineers, Atlanta, GA, USA, pp. 1056-1076

7. V.D. Wymelenberg, Kevin, Energy Build. 51, 165 (2012)

8. S. Pigg, M. Eilers, J. Reed, Behavioral aspects of lighting and occupancy sensors in private offices: a case study of a University office building, in ACEEE Summer Study on Energy Efficiency in Buildings, 1996, p. 8.161

9. V. Inkarojrit, Balancing comfort: occupants' control of window blinds in private offices, Thèse en Architecture, University of California, Berkeley, 2005

10. N. Fergus, M. Wilson, C. Chiancarella, Energy Build. 38, 802 (2006)

11. M.S. Rea, Build. Environ. 19, 133 (1984)
12. A. Mahdavi, Indoor Built Environ. 18, 440 (2009)

13. I. Rubin, L. Arthur, B. Collins, L. Robert, Tibbott, Window blinds as a potential energy saver - a case study, NBS Building sciences series, $\mathrm{N}^{\circ} 112,1978$

14. D.S. Correia, Pedro, V. Leal, M. Andersen, Build. Environ. 64, $152(2013)$

15. M. Bonte, Influence du comportement de l'occupant sur la performance énergétique du bâtiment. Thèse en Énergétique et Transferts, Université Paul Sabatier, Toulouse, 2014, 206 p.

16. J.-H. Kim, Y.J. Park, M.S. Yeo, K.W. Kim, Build. Environ. 44, 1517 (2009)

17. C.F. Reinhart, K. Voss, Light. Res. Technol. 35, 243 (2003)

18. F. Haldi, R. Darren, Build. Environ. 44, 2378 (2009)

19. A. Persily, Build. Environ. 91, 61 (2015)

20. M.W. Liddament, Air Infiltration and Ventilation Centre \& IEA Energy Conservation in Buildings and Community Systems Programme Annex V Air Infiltration and Ventilation Centre, "A guide to energy efficient ventilation". Air Infiltration and Ventilation Centre, Coventry, England, 1996

21. C.A. Roulet, L. Vandaele, Air Infiltration and Ventilation Centre \& IEA Energy Conservation in Buildings and Community Systems Programme Annex V Air Infiltration and Ventilation Centre, "Technical note AIVC 34: airflow patterns within buildings measurement techniques". AIVC, IEA, 1991

22. C.A. Roulet, H. Awbi, Ventilation systems: design and performance (Taylor \& Francis, 2007)

23. Norme ASHRAE 129: Measuring Air Change Effectiveness, 2002

24. D. Al Assaad, K. Ghali, N. Ghaddar, C. Habchib, Energy Build. 154, 569 (2017)

25. A. Schieweck et al., Renew. Sustain. Energy Rev. 705 (2018) 26. P. Wolkoff, Int. J. Hygiene Environ. Health 376 (2018)

27. S. Morsli, H. Ramenah, M. El Ganaoui, R. Bennacer, Eur. Phys. J. Appl. Phys. 83, 10901 (2018)

28. S. Morsli, M. Boussoufi, A. Sabeur, M. El Ganaoui, R. Bennacer, Int. J. Numer. Methods Heat Fluid Flow 28, 188 (2018)

29. Fluent Inc., FLUENT 6.3.26 User's guide (Fluent Inc., 2006)

Open Access This article is distributed under the terms of the Creative Commons Attribution License https://creativecom mons.org/licenses/by/4.0 which permits unrestricted use, distribution, and reproduction in any medium, provided the original author(s) and source are credited.

Cite this article as: Souad Morsli, Rachid Bennacer, Mohammed El Ganaoui, Harry Ramenah, Alain Carmasol, Some flow patterns within ventilation strategy coupled to energy efficiency, Eur. Phys. J. Appl. Phys. 88, 10902 (2019) 